\title{
Formação do bibliotecário brasileiro no contexto da competência em dados
}

Formation of the brazilian librarian in the context of data literacy

La formación de los bibliotecarios brasileños en el contexto de la competencia en materia de datos

Marcelle Costal Instituto Brasileiro de Informação em Ciência e Tecnologia-

IBICT/UFRJ

Brasil

Marianna Zattar

Universidade Federal do Rio de Janeiro (UFRJ)

Brasil

Luana Sales Instituto Brasileiro de Informação em Ciência e Tecnologia-

IBICT/UFRJ

Brasil

Submetido em: 23/04/2021

Aceito em: 14/06/2021

Publicado em: 28/10/2021

Licença:

(c) (i)

Autor para correspondência: Marcelle Costal

Email: costalcastro@gmail.com

ORCID: https://orcid.org/0000-0001-5898-9163

Como citar este artigo:

COSTAL, Marcelle; ZATTAR, Marianna; SALES, Luana. Formação do bibliotecário brasileiro no contexto da competência em dados

REBECIN, São Paulo, v. 8, número especial, p. 01-13, 2021. DOI: 10.24208/rebecin.v8i.264. 


\section{RESUMO}

Propõe estudar a formação dos bibliotecários na graduação em nível nacional nos aspectos relacionados à competência em informação e à gestão de dados de pesquisa. Para tal, serão abordados no referencial teórico a relação entre a competência em informação e a competência em dados de pesquisa. Utiliza como procedimento metodológico uma abordagem qualitativa, realizada a partir de um método exploratório e descritivo. Apresenta a coleta de dados elaborada em buscas no site do Cadastro Nacional de Cursos e Instituições de Educação Superior (eMEC) para verificação dos cursos de Biblioteconomia, que em suas ementas, promovem o uso da competência em informação relacionada aos processos da gestão de dados de pesquisa. Apresenta como principais resultados que a competência em informação e a gestão de dados de pesquisa são temas incipientes na formação inicial do bibliotecário brasileiro. Conclui que a competência em dados, um ramo da competência em informação, no ensino de graduação, pode projetar as práticas biblioteconômicas para atender as necessidades dos pesquisadores quanto às etapas que envolvem a gestão de dados de pesquisa.

Palavras-Chave: Formação do bibliotecário; Competência em informação; Competência em dados; Gestão de Dados de Pesquisa; Dados de pesquisa.

\section{ABSTRACT}

It proposes to study the librarian formation in undergraduate courses at the national level in aspects related to information literacy and research data management. The relationship between information literacy and data literacy will be addressed in the theoretical framework. It uses as a methodological procedure a qualitative approach, carried out from an exploratory and descriptive method. It presents the data collection elaborated in searches on the website of the Cadastro Nacional de Cursos e Instituições de Educação Superior (e-MEC) to verify the courses of Librarianship, which in their menus, promote the use of information literacy related to the management processes of search survey data. It presents as main results that the information literacy and the research data management are incipient themes in the initial formation of the Brazilian librarian. It concludes that data literacy, a branch of information literacy, in 
undergraduate education can design library practices to meet research needs regarding the steps that involve research data management.

Keywords: Librarian formation; Information literacy; Data literacy; Research data management; Research data.

\section{RESUMEN}

Se propone estudiar la formación de los bibliotecarios a nivel nacional de pregrado en aspectos relacionados con la competencia informativa y la gestión de datos de investigación. Para ello, en el marco teórico se abordará la relación entre la competencia informativa y la competencia en materia de datos de investigación. Utiliza como procedimiento metodológico un enfoque cualitativo, realizado desde un método exploratorio y descriptivo. Presenta la recopilación de datos elaborada en búsquedas en el sitio del Registro Nacional de Cursos e Instituciones de Educación Superior (e-MEC) para verificar los cursos de Bibliotecología, que en sus menús, promueven el uso de la competencia en información relacionada con los procesos de gestión de datos de investigación. Presenta como principales resultados que la competencia en información y gestión de datos de investigación son temas incipientes en la formación inicial del bibliotecario brasileño. Concluye que la competencia en materia de datos, una rama de la competencia en materia de información, en la formación de grado, puede diseñar prácticas bibliotecarias para satisfacer las necesidades de los investigadores en relación con los pasos que implican la gestión de los datos de investigación.

Palabras clave: Educación bibliotecaria; competencia informativa; competencia de datos; gestión de datos de investigación; datos de investigación.

\section{INTRODUÇÃO}

No contexto internacional, em que a temática da gestão de dados de pesquisa (GDP) vem sendo debatida há mais de uma década, Carlson et al. (2011) relatam que os profissionais da informação, em especial os bibliotecários, começaram a entender a necessidade de desenvolver 
meios que auxiliem as pessoas a superar os novos desafios trazidos pela tecnologia referentes à competência em dados.

A gestão de dados de informação é competência do bibliotecário, já que de acordo com Calzada Prado e Marzal (2013) as bibliotecas, por já desenvolverem a competência em informação (Colnfo), estão bem posicionadas também para desenvolverem a competência em dados. Em vista disso, a competência em dados, no que tange aos dados digitais, está conectada à Colnfo, uma vez que ela e as demais competências fornecem estruturas e atividades que ajudam a compreender o mundo digital, que também está sujeito à ação humana.

Urge a necessidade de desenvolver na formação do bibliotecário habilidades em competência em dados para que este possa permitir que os pesquisadores acessem, interpretem, avaliem criticamente, gerenciem, manipulem e usem os dados eticamente (CALZADA PRADO; MARZAL, 2013). O bibliotecário precisa aprimorar suas habilidades em sua função de educador no fomento da Colnfo dentro e fora da biblioteca.

No entanto, verifica-se que no Brasil há uma incipiência da figura do "bibliotecário de dados" no escopo das discussões sobre a sua atuação, bem como no desenvolvimento de métodos e práticas relacionadas à competência em dados no escopo da Ciência da Informação brasileira (TARTAROTTI; DAL'EVEDOVE; FUJITA, 2019). Somado a isso, é preciso que os cursos de graduação em Biblioteconomia apostem em formação sobre Colnfo e, por conseguinte, na competência em dados. Esta temática pode ser explorada por meio das ementas das disciplinas de Colnfo e fontes de informação ofertadas pelos cursos de graduação em Biblioteconomia no Brasil. 
Deste modo, esta pesquisa tem por objetivo averiguar como se dá a formação do bibliotecário no Brasil em nível de graduação, nos aspectos relacionados à Colnfo e à GDP. Para tal, foi consultado, em março de 2019, o Cadastro Nacional de Cursos e Instituições de Educação Superior no Brasil (BRASIL, 2019) sobre os cursos de graduação em atividade da área de Biblioteconomia, para investigar nas ementas das disciplinas dos cursos como vêm sendo abordadas as temáticas sobre a GDP. Esta pesquisa é o resultado do trabalho de conclusão do curso de Biblioteconomia e Gestão de Unidades de Informação (CBG), da Universidade Federal do Rio de Janeiro (UFRJ), apresentado por Costal (2019).

\section{A RELAÇÃO DA COMPETÊNCIA EM INFORMAÇÃO E COMPETÊNCIA EM DADOS}

Percebe-se que a Colnfo possui dimensões de cunho prático envolvendo o uso de fontes, recursos informacionais e o aprendizado sobre as tecnologias de informação e comunicação (TIC) e o treinamento de softwares. Somado a isso, inclui uma compreensão sobre o contexto humano, cultural, sociológico, político, filosófico e histórico do desenvolvimento de uma infraestrutura de informação que espelhem pensamento críticos e éticos. De acordo com Shapiro e Hughes (1996, p. 3, tradução nossa):

[...] se estende desde saber usar computadores e acessar informação até a reflexão crítica sobre a própria natureza da informação, sua infra-estrutura técnica, seu contexto e impacto social, cultural e até filosófico. 
Um novo aspecto trazido pela Association of College and Research Libraries (ACRL) (2015) à Colnfo é que além das dinâmicas de mudanças no "mundo da informação" e no "uso de informações" é preciso que os indivíduos construam também novos conhecimentos e compreendam as dinâmicas a partir de "dados", um outro tipo de formato que dentro de um contexto em comunidade, também pode ser um repositório de informação. Outrossim, Zattar (2020) entende que a Colnfo está presente em todas as atividades de aprendizagem construídas de forma contínua, comunitária, coletiva e solidária, sendo uma "prática sociotécnica" que permite saber quando a informação é oportuna e por meio disso "saber localizar, avaliar e utilizar a informação de forma eficaz, crítica e ética". É uma atividade complexa que se desenvolve em meio às dinâmicas de aprendizagem que possuem particularidades inatas ao contexto e se desenvolve a partir de "[...] todos os tipos de formatos, suportes e conteúdos informacionais". (ZATTAR, 2017, p. 8).

Não obstante, a Colnfo por si só não dá conta de cuidar de uma multiplicidade conceitual atribuída a mudanças nos mais variados ambientes e contextos de informação, sendo assim, a competência em dados torna-se uma dimensão da Colnfo (KOLTAY, 2017a). Em vista disso, a competência em dados, no que tange aos dados digitais, está conectada à Colnfo, uma vez que ela e as demais competências fornecem estruturas e atividades que ajudam a compreender o mundo digital, que também está sujeito à ação humana.

A competência em dados é uma destas tentativas de trazer uma nova faceta ao mundo da Colnfo na contribuição para uma educação que torne os indivíduos mais preparados para lidar com este tipo de 
informação. Koltay (2017b), à semelhança da sobrecarga de informação, apresenta a sobrecarga de dados nas ciências. $E$ do mesmo modo que é necessária à Colnfo para tentar compreendê-la, é importante à competência em dados, indicando que ambas possuem laços estreitos, mas possuem suas especificidades de domínio. Em uma aproximação entre ambas, tem-se a qualidade de dados e a avaliação crítica de fontes e de dados. Carlson et al. (2013) entendem que os programas de competência em dados também devem estar alinhados a uma cultura disciplinar, ao mesmo tempo em que devem atuar na autonomia de indivíduos e pesquisadores.

De acordo com Calzada Prado e Marzal (2013), a competência em dados (data literacy) está na capacidade de definir com precisão a necessidade de informação, localizar fontes de informação adequadas em dados, assim como a capacidade de avaliar criticamente as fontes de informação e as ideias nelas expressas. Somado a isso, tem-se a capacidade de gerenciar as informações selecionadas nas fontes e a capacidade de analisar e sintetizar informações para apoiar argumentos ou gerar novas ideias; bem como a de documentar as fontes utilizadas; e a capacidade de registrar ou comunicar os resultados de maneira ética (CALZADA PRADO, MARZAL, 2013).

Carson et al. (2013) apontam que no escopo da competência em informação está uma expansão lógica e conceitual que caminha para a curadoria e gestão de dados. Ou seja, a competência em dados é a capacidade de desenvolver habilidades e competências sobre os processos que envolvem a GDP, desde o seu planejamento, compartilhamento e reuso, em sua dimensão técnica, tecnológica, no seu contexto social, cultural, filosófico e histórico no qual os dados surgem. 
Deste modo, esta pesquisa se propôs investigar nas ementas das disciplinas a Colnfo e a GDP, uma vez que o termo competência em dados não está consolidado nos debates sobre o processo de GDP.

\section{PROCEDIMENTOS METODOLÓGICOS}

A metodologia aplicada a este trabalho possui uma abordagem qualitativa, realizada a partir de um método exploratório e descritivo de acordo com as premissas de GIL (2002), no levantamento e descrição de características a partir de materiais que ainda não receberam tratamento analítico. Deste modo, objetivo desta pesquisa tem por finalidade identificar os cursos brasileiros em Biblioteconomia, a fim de obter as ementas de disciplinas que incluam a Colnfo e a GDP, para analisar como vem sendo construída a formação do bibliotecário nos assuntos respectivos à gestão de dados de pesquisa.

O campo de pesquisa configura-se em ambiente web e os cursos de graduação em atividade da área de Biblioteconomia foram identificados a partir do Cadastro Nacional de Cursos e Instituições de Educação Superior no Brasil, em março de 2019, por meio da base de dados "e-MEC" (Ministério de Educação). As ementas seriam obtidas, caso estivessem disponíveis online, por meio do acesso aos portais das respectivas universidades cadastradas.

\section{RESULTADOS E DISCUSSÃO}

Em consulta à base de dados "e-MEC", foram identificados 57 cursos de graduação em Biblioteconomia credenciados. Dentre eles, 6 cursos ainda não foram iniciados e 3 foram extintos. Embora todos os 48 
cursos em atividade possuam acesso online, somente 39 cursos possuíam currículos com ementas de disciplinas disponíveis. A apresentação das disciplinas estava disponível em seus portais oficiais ou blogs acadêmicos, por meio das políticas do curso, ementas, fluxogramas, ou quadros, em muitas situações sem uma descrição apropriada dos temas abordados. A recuperação das disciplinas foi feita pelos termos "competência em informação", "alfabetização informacional", "competência informacional", "dados" e "curadoria digital". A fim de não perder nenhuma informação, fez-se uma revisão observacional em cada descrição de ementas.

Identificou-se que 25 cursos de graduação em Biblioteconomia trabalham temáticas de dados em seus currículos, mas em 23 instituições a perspectiva se dava pelo planejamento e gestão de bases de dados bibliográficas. Entretanto, duas instituições apresentam disciplinas que podem trabalhar com assuntos relacionados aos dados de pesquisa. Neste caso, sob a perspectiva da gestão, tem-se a Universidade Federal de Minas Gerais (UFMG) e a Universidade Federal do Rio Grande do Sul (UFRGS). A UFMG sugere como título de disciplina uma optativa em "Tópicos em Tecnologia da Informação", com as temáticas "Noções de Algoritmo e Estrutura de Dados", "Gerência de Dados na Web" e "Preservação Digital". A UFRGS oferece como optativa a disciplina "Curadoria Digital Fundamentos e Aplicações", que apresenta em sua ementa seu contexto histórico, partindo de princípios fundamentais que dizem respeito aos processos de seleção, preservação, descrição, manutenção, coleção e arquivamento de ativos ou dados digitais, considerando a continuidade e compatibilidade semântica e ontológica de conteúdo, na perspectiva de unidades de informação da internet. Outra 
optativa da UFRGS é a disciplina "Informação e Acesso Aberto", que se propõe a delinear o sistema de comunicação científica para o acesso aberto, bem como a estrutura política do sistema de acesso aberto, suas tecnologias e novos modos de publicação. Estas temáticas, ainda que as ementas não ofereçam muita informação, são aspectos da gestão de dados de pesquisa.

Sob o ponto de vista da "competência em informação", recuperouse 7 instituições que apresentam com a oferta em seus currículos disciplinas sobre a Colnfo. Contudo, somente a proposta disciplinar da UFMG com o título "Competência Informacional" (obrigatória), é que tem por escopo os aspectos históricos do movimento da competência informacional a partir da perspectiva do letramento informacional para o desenvolvimento de habilidades em "diferentes suportes". Neste aspecto, pode-se incluir como suporte à informação os dados de pesquisa, uma vez que conforme Buckland (1991) os dados, uma vez contextualizados, podem evidenciar algum aprendizado.

Assim, observa-se que a Colnfo relacionada aos processos de GDP ainda se configura como um tema incipiente em disciplinas dos cursos de graduação brasileiros em 2019, ano da consulta ao portal "e-MEC".

\section{CONSIDERAÇÕES FINAIS}

Com a elaboração deste trabalho, foi possível perceber que os currículos dos cursos, credenciados pelo MEC, apresentam de forma incipiente disciplinas relativas à competência em informação e à GDP. Aliás, de acordo com a investigação, são poucos os cursos que possuem em suas ementas a disciplina GDP ou Colnfo da qual, conforme Koltay 
(2015), a competência em dados é um fragmento, por se aproximar metodologicamente de uma abordagem crítica e pelo interesse da competência em informação da compreensão adequada ao uso de dados que são convertidos em informação. Assim sendo, os cursos em Biblioteconomia no Brasil não ofertam disciplinas ou descrições que alinhem a Colnfo à GDP, como a exemplo do termo "competência em dados".

Percebe-se que a competência em dados na formação dos bibliotecários pode projetar as práticas biblioteconômicas para atender as necessidades dos pesquisadores quanto às etapas que envolvem os dados de pesquisa. Nesta dinâmica é urgente fazer com que os bibliotecários obtenham conhecimento em dados. Ao mesmo tempo uma educação em dados atua na sensibilização para a formação de profissionais de gerenciamento de dados num constructo de habilidades necessárias para se trabalhar como um bibliotecário de dados.

\section{REFERÊNCIAS}

ASSOCIATION OF COLLEGE AND RESEARCH LIBRARIES (ACRL). Framework for information literacy for higher education. Chicago: ACRL, 2015. Disponível em: http://www.ala.org/acrl/standards/ilframework. Acesso em: 17 abr. 2021.

BRASIL. Ministério da Educação. Cadastro nacional de cursos e instituições de educação superior: cadastro e-MEC. Brasília, DF: MEC, 2019. Disponível em: http://emec.mec.gov.br/. Acesso em: 10 mar. 2019.

BUCKLAND, M. K. Information as thing. Journal of the American Society for Information Science, Nova Jersey, v. 45, n. 5, p. 351-360, 1991. 
CALZADA PRADO, J.; MARZAL, M. A. Incorporating data literacy into information literacy programs: core competencies and contents. Libri, [s. I.], v. 63 , n. 2, p. 123-134, 2013. DOI: https://doi.org/10.1515/libri-20130010.

CARLSON, J. R. et al. Determining data information literacy needs: a study of students and research faculty. Libraries and the Academy, Baltimore, v. 11, n. 2, p. 629-657, 2011.

CARLSON, J. R. et al. Developing an approach for data management education: a report from the data information literacy project. International Journal of Digital Curation, [S. I.], v. 8, n. 1, p. 204-217, 2013. DOI: 10.2218/ijdc.v8i1.254.

COSTAL, M. Competência em informação para gestão de dados de pesquisa: um olhar para a formação do (a) bibliotecário (a).

Orientadora: Marianna Zattar. 2019. Trabalho de Conclusão de Curso (Bacharelado em Biblioteconomia e Gestão de Unidades de Informação) - Universidade Federal do Rio de Janeiro, Rio de Janeiro, 2019.

GIL, A. C. Como elaborar projetos de pesquisa. 4. ed. São Paulo: Atlas, 2002.

KOLTAY, T. Data literacy for researchers and data librarians. Journal of Librarianship and Information Science, Newbury Park, v. 49, n. 1, p. 3-14, 2017a.

KOLTAY, T. Data literacy: in search of a name and identity. Journal of Documentation, Bingley, v. 71, n. 2, p. 401-415, 2015. DOI: https://doi.org/10.1108/JD-02-2014-0026.

KOLTAY, T. The bright side of information: ways of mitigating information overload. Journal of Documentation, Bingley, v. 73, n. 4, p. 767-775, 2017b. DOI: https://doi.org/10.1108/JD-09-2016-0107.

SHAPIRO, J. J.; HUGHES, S. K. Information literacy as a liberal art: enlightenment proposals for a new curriculum. Educom Review, [s. I.], v. 31, n. 2, p. 1-6, 1996. Disponível em:

https://teaching.uncc.edu/sites/teaching.uncc.edu/files/media/articlebooks/InformationLiteracy.pdf. Acesso em: 3 set. 2020. 
TARTAROTTI, R. C. D.; DAL'EVEDOVE, P. R.; FUJITA, M. S. L.

Biblioteconomia de dados em repositórios de pesquisa: perspectivas

para a atuação bibliotecária. Informação \& Informação, Londrina, v. 24, n. 3, p. 207-226, 2019. DOI: http://dx.doi.org/10.5433/19818920.2019v24n3p207. Disponível em:

http://www.uel.br/revistas/uel/index.php/informacao/article/view/38732. Acesso em: 7 nov. 2020.

ZATTAR, M. Competência em Informação e Desinfodemia no contexto da pandemia de Covid-19. Liinc em Revista, Rio de Janeiro, v. 16, n. 2, p. 1-13, 2020. DOI: https://doi.org/10.18617/liinc. Disponível em: http://revista.ibict.br/liinc/article/view/5391/5112. Acesso em: 18 abr. 2021.

ZATTAR, M. Competência em mídia e em informação no ensino: um breve relato de experiência. Revista Brasileira de Biblioteconomia e Documentação, São Paulo, v. 13, n. especial, p. 272-279, 2017. Disponível em: https://rbbd.febab.org.br/rbbd/article/view/664. Acesso em: 26 jul. 2020. 